\section{An ape from the south}

\section{Peter Andrews}

DISCOVERIES of fossil hominoids from the first half of the Miocene, 24 to 15 million years ago (Myr), have been restricted mainly to eastern Africa. On page 144 of this issue ${ }^{1}$, Conroy et al. describe a fossil hominoid jaw from the Miocene of Namibia, thus extending the range of Miocene hominoids down well into southern Africa. The specimen will be the centrepiece of a workshop, Apes or ancestors?, to be held at the American Museum of Natural History, New York, on 28 March.

Combined with other discoveries in northern Kenya ${ }^{2,3}$ and Saudi Arabia ${ }^{4}$, the new find shows that by the end of the first half of the Miocene the distribution of hominoids extended almost the full length of the African continent (at this time the Arabian peninsula was geographically part of Africa). Soon afterwards, hominoids apparently dispersed out of Africa, the first record being from Paşalar, Turkey ${ }^{5.6}$, dated 14-15 Myr. About three million years later they are known from the south of France in the west to Pakistan in the east, and they extended their range to China later in the Miocene. To some extent, this is paralleled by the present distribution of apes in Africa and southeast Asia, but whereas today the apes are almost entirely restricted to tropical forest, their Miocene distribution was rather more extensive.

\section{Relationships}

In accounting for this notable difference in distribution between past and present hominoids, the phylogenetic relationship of the fossil species is critical. Conroy species. and colleagues assign the Namibian hominoid to a new genus and species on the grounds that it exhibits a unique constellation of characters that differentiate it from other middle-Miocene hominoids. They suggest a number of possibilities for its relationships: it may be (1) the sister-group to all large-bodied hominoids; (2) sister-group to the African ape and human clade; (3) sistergroup to the African ape clade; and (4) sister-group to the human clade. Because the evolutionary relationships of most previously known Miocene hominoids could be more precisely determined than that, the value of this discovery would be tempered by its very uniqueness, precluding its association with any other fossil group. But is the new specimen really that unique?

The basis for the uniqueness of the Namibian hominoid is provided by the 12 characters listed in the generic diagnosis by Conroy et al. on page 144. Five of them appear to support the idea that it is the sister-group to all large-bodied hominoids, but none at all can be found to support the other three possibilities (see the table accompanying this article). Several characters are of doubtful significance, and only two or three distinguish the Namibian hominoid from other fossil

Many of the characters, however, are shared with the older fossil hominoid Afropithecus, and it would have been interesting if the Namibian hominoid could have been compared with Afropithecus in this paper. More detailed examination may support the generic distinction, but on the evidence pub-

ANALYSIS OF THE 12 CHARACTERS OF THE NAMIBIAN HOMINOID*

Characters supporting sister-group relationship with the great ape (orang utan, chimpanzee and gorilla) and human clade

1 'Puffy' molar cusps with Y5 pattern

2 Absence of beaded buccal cingulum

3 Presence of protostylar ridges on $M_{2}$ and $M_{3}$

6 Moderate size of inferior transverse torus

10 Little differential wear on molars

Characters probably ancestral for all hominoids

8 Molar wear indicating thin enamel

12 Narrow incisor region

Characters of unknown significance

7 Large retromolar space

$9 M_{3}$ not obscured by ascending ramus (same as 7)

Possible unique characters in the Namibian hominoid

4 Square molars

$5 \mathrm{M}_{2}>\mathrm{M}_{3}>\mathrm{M}_{1}$

11 Even depth of mandible

Characters shared between the Namibian hominoid and Afropithecus $1,2,4,6,11,12$

* Numbers and characters refer to the list of Conroy et al. on page 144. lished here it would not appear to be justified.

The species distinction, on the other hand, seems to be well founded, based as it is on an argument implicit in the paper. This is that, whereas many or most of its characters are present in other Miocene hominoids, there is none that shares them all, and it is the pattern of characters that is used as the speciesdefining complex. Le Gros Clark ${ }^{7}$ restricted his concept of total morphological pattern to functionally related characters and my own extension to this was to infer that a functionally related character complex may be a stronger phylogenetic tool than single characters taken in isolation $^{8}$

\section{Principles}

How do these principles apply to the new hominoid? The 'squared-off' molars (character 4 of the generic diagnosis in Conroy et al.) might relate functionally to the large retromolar space (characters 7 and 9), and to the large size of the second molar relative to the others (character 5). Such a combination might be related to the presence of thin enamel (but see ref. 9) and the little differential wear on the molars (characters 8 and 10), this pattern perhaps indicating a dietary function (eating of soft fruit) little different from that of Proconsul ${ }^{10}$. It would have been interesting to have had the authors' views on the significance of such a pattern, which may also be present in Afropithecus - although the Namibian hominoid is smaller than the type species of that genus, it is similar in size to the referred species $A$. leakeyi (= Heliopithecus leakeyi Andrews \& Martin 1987) from Saudi Arabia.

It is a fascinating speculation that the furthest southwards extension of the hominoid range in the Miocene was phylogenetically linked with the furthest northwards extension of similar age. But speculation is all that it remains in the absence of a more rigorous taxonomic interpretation of this important discovery in Namibia.

Peter Andrews is in the Department of Palaeontology, Natural History Museum, London SW7 5BD, UK.

1. Conroy, G. C., Pickford, M., Senut, B., Van Couvering, J. \& Mein, P. Nature 356, 144-148 (1992).

2. Leakey, R. E. \& Leakey, M. G. Nature 324, 143-146 (1986)

3. Leakey, R. E. \& Leakey, M. G. Nature 324, 146-148 (1986).

4. Andrews, P. \& Martin, L. Bull. Br. Mus. nat. Hist. 41 383-393 (1987).

5. Alpagut, B., Andrews, P. \& Martin, L. J. hum. Evol. 19 397-422 (1990).

6. Bernor, R. \& Tobien, H. J. hum. Evol. 19, 551-568 (1990).

7. Le Gros Clark, W. E. Fossil Evidence for Human Evolution (Chicago University Press, 1955).

8. Andrews, P. in Molecules and Morphology (ed. Patterson, C.) 21-53 (Cambridge University Press, 1987)

9. Grine, F. E. Palaeont. afr. 28, 61-69 (1991).

10. Kay, R. F. Nature 268, 628-630 (1977) 